\title{
Fault Diagnosis For Exhaust Fan Using Experimental Predictive Maintenance Method
}

\author{
Hamdi Taplak \\ Mechanical Engineering Department, Erciyes University, 38039 Kayseri, Turkey
}

Emrah Kurt

Afsin-Elbistan Thermal Power Plant, Kahramanmaras, Turkey

\begin{abstract}
Mehmet Parlak
Department of Mechanical Engineering, Faculty of Engineering and Architecture, Nevsehir Haci Bektas Veli University, Nevsehir, Turkey

Graduate School of Natural and Applied Sciences, Erciyes University, Kayseri 38039, Turkey
\end{abstract}

(Received 23 June 2014; accepted: 3 February 2015)

\begin{abstract}
Unexpected machine failures cause a decrease in production and increase in cost so that predictive maintenance methods have everyday importance. The main principle of predictive maintenance methods is to decide maintenance time of machines by monitoring machine performance during operations and resolving the failure when the machines stop.

In this study, failures of the exhaust fan system used in Afsin-Elbistan B Thermal Power Plant were monitored by using predictive maintenance methods that rely on vibration analysis. The failures were periodically measured from four points on the bearings of fans and motors with a vibration analyzer. Identified failures on the system have been respectively removed with analysis of measurements. After all failures have been removed, it has been noted that vibration values decreased when measured again from the aforementioned four point. With using the predictive maintenance method, failures can be identified before the failures cause negative results whereby both unnecessary machine stops can be prevented and the cost of operation can be decreased.
\end{abstract}

\section{INTRODUCTION}

In practical applications, predictive maintenance can use different techniques, such as the analysis of vibrations, the analysis of the potential contaminants in the lubrication system, the control of energy consumption, the control of the temperature in selected positions or the analysis of the noise generated by the machine; in conclusion, the measurement of the parameter or parameters that could be considered representative of the operation of the machine. Among these techniques, the analysis of vibration is the most frequently used and undoubtedly the most effective technique to detect mechanical defects in rotating machinery. ${ }^{1,2}$ The maintenance based on the analysis of vibration has been enforced in plants that have mass production since the 1970's. Petroleum, chemical, steel, and paper industries have adopted this technique and have increased their rate of profit thanks to an increment of production and fewer machine stops.

Unexpected machine failure cause both hitch of production schedule and increasing cost with financial loss, which explains why maintenance based on vibration analysis has high importance in industry. The main principles of predictive maintenance include monitoring the machine performance during production, determining the maintenance time and turning off the machine at a convenient time to resolve the predetermined faults.
Even well-designed machines experience slight vibration. The machine elements wear off through continued use. Some machine elements might be deformed, and their dynamical features may change. Clearance between elements, that run together, increases eccentirity and cause imbalance problems. All of these factors cause rising vibration amplitude. Information about machine condition can be obtained by analyzing the vibrations.

When the machines have specific failures, they give some signal intended for the failures. The best signal can be obtained from vibrations of the machines. A vibration is a reaction force against internal and external forces of mechanical elements of a machine. Vibration analyses offer good results on the rotating machines, especially fans, pumps, engines, and gearboxes. There is a great deal of literature available that describes the type of vibration signals to be expected for faults in typical systems and the analysis tehniques that can be used for early detection of faults. ${ }^{3}$

The vibration analysis technique includes vibration measurement and its evaluation. First, vibration signals are collected by the vibration analyzer equipped with a sensor in the time domain by processing FFT, and the information gained from the vibration signals can be used to predict failures, to reduce vibration and to repair failures caused by vibration. ${ }^{4}$

Failures commonly found in fans include imbalance, misalignment, looseness, bearing fault, gear fault, hydraulic and 
aerodynamic problems, resonance, etc. In this study, mechanical looseness, bearing faults, rubber damper faults, and engine faults in the used systems were determined using predictive maintenance techniques and have been resolved. Some studies on the topic of fault detection have been done by using the vibration analysis. Orhan et al. presented and examined the vibration monitoring and analysis case studies in machineries that were running in real operating conditions. They determined the failures on the machines in their early stages by using the spectral analysis. ${ }^{4}$

Trebuna et al. analyzed causes of excessive vibration of one of the two fans in the steelworks that provide exhaustion of vapor and residues produced during melting of steel scrap. During operation, the excessive vibration of the problematic fan led to the initiation of cracks in the concrete foundation and the repeated damage to the bearings. Under such conditions, whole equipment can be damaged and collapse. A complex approach was applied to solve this problem. The approach includes experimental and numerical modal analysis of the fan's rotating wheel as well as a series of operational measurements to assess the actual technical condition of the problematic fan and determine possible damages. ${ }^{5}$

McFadden and Smith have modelled the vibration that has been created by single and multiple damages in the inner race of rolling element bearing and have verified the obtained results with experimental results. ${ }^{6}$

Akturk and Gohar have conducted studies on a shaft-bearing system. Change of ball size in the bearing has been investigated regarding the effects of radial and axial vibration. In order to do this, they have created a software and presented results on time-frequency domain. ${ }^{7}$

Ibrahim et al. described the application of vibration analysis technique in the diagnosis of cooler fan of a centrifugal compressor high vibration. To describe this, they collected the data from machinery and showed that the vibration amplitudes for radial directions tend to be high near the coupling of motortogear input by analyzing the data. After essential works have been realized, they managed to reduce and fix, within the acceptable limits the vibration amplitude. ${ }^{8}$

Geramitchioski and Trajcevski investigated vibration produced by rolling bearings defect in the motor-fan machinery and showed the procedure for prediction of rolling bearings defect. $^{9}$

Albraik et al. investigated the correlations between pump performance parameters and surface vibration for the purpose of both pump condition monitoring and performance assessment. They used five impellers to investigate and compare relations between damaged and healthy pump: one impeller in good condition and four others with different defects. ${ }^{10}$

Spychala et al. investigated damages of military aerial ships after exploitation and obtained the vibration answer on simulated damages. ${ }^{11}$

Choi et al. studied to find out the cause of high vibration at cyrogenic pumps-motor system in LNG terminal. They estimated motor rotor bar problems by the vibration analysis and confirmed the results with current analysis. ${ }^{12}$

Ali et al. studied on the effects of working under different speeds at two loading conditions on an electric motor. They

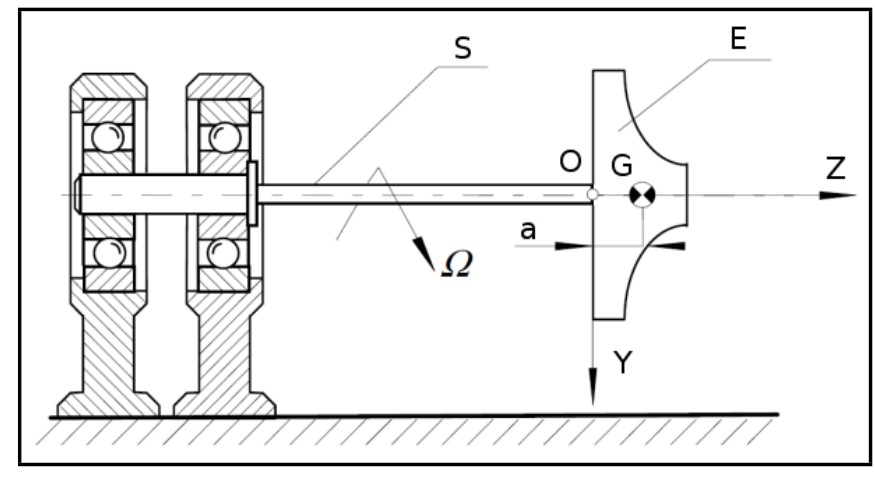

Figure 1. Physical model of fan. ${ }^{14}$

showed that the vibration amplitude was affected by changing both load and speed. ${ }^{13}$

As seen on the publications, vibration analysis technique is frequently used to determine the faults. In these publications, researchers only focused to estimate one fault by vibration analysis. In this study, such as mechanical looseness, bearing faults, rubber damper faults, and engine faults, four different faults in the used systems had been determined with predictive maintenance technique and the faults have been resolved. In addition, the difference in vibration level between before and after maintenance can be clearly seen in Table 2 .

\section{THEORY}

\subsection{Determining the Physical and Mathematical Model of the System}

Rotor system seen in Fig. 1 represents the physical model of the exhaust fan. Let us accept shaft ' $S$ ' on this model is flexible and has no mass. Let us consider fan disc element 'E' as a rigid object fixed to shaft at the point 'O'. Point $O$ is choosen as the centre of $\mathrm{XYZ}$ absolute system coordinates. Gravity centre ' $G$ ' is far away as 'a' from origin ' $O$ '. This disc element has the mass of ' $\mathrm{m}$ ' and $\mathrm{Z}$ axis is the symmetry axis of the object. Because of this inertia moment on $\mathrm{X}$ and $\mathrm{Y}$ axis are equal and defined as $I_{x}=I$ and $I_{y}=I$. The rotor is rotating with angular velocity of ' $\Omega$ '. ${ }^{14}$ In this situation, mathematical model of the system is

$$
m \ddot{X}+c \dot{X}+k X=F_{G} ;
$$

where

$$
\begin{array}{r}
m=\left[\begin{array}{cccc}
m & 0 & m a & 0 \\
0 & m & 0 & m a \\
m a & 0 & I+m a^{2} & 0 \\
0 & m a & 0 & I+m a^{2}
\end{array}\right] \\
k=\left[\begin{array}{cccc}
k_{11} & 0 & k_{12} & 0 \\
0 & k_{11} & 0 & k_{12} \\
k_{21} & 0 & k_{22} & 0 \\
0 & k_{21} & 0 & k_{22}
\end{array}\right] c=\left[\begin{array}{cccc}
0 & 0 & 0 & 0 \\
0 & 0 & 0 & 0 \\
0 & 0 & 0 & I_{z} \Omega \\
0 & 0 & -I_{z} \Omega & 0
\end{array}\right] \\
X=\left[\begin{array}{c}
X \\
Y \\
f_{X} \\
f_{Y}
\end{array}\right] F_{G}=\left[\begin{array}{c}
0 \\
m g \\
0 \\
m g a
\end{array}\right] ;
\end{array}
$$


Equations of motion of the rigid element are

$$
\begin{array}{r}
m \ddot{x}+m a \ddot{f}_{x}=F_{x}+U F_{x} \\
m \ddot{y}+m a \ddot{f}_{y}=F_{y}+m g+U F_{y} ; \\
I \ddot{f}_{z}+I_{z} \Omega \dot{f}_{y}=M_{x}-F_{x} a+U M_{x} \\
I \ddot{f}_{y}+I_{z} \Omega \dot{f}_{x}=M_{y}-F_{y} a+U M_{y} .
\end{array}
$$

Mathematical model of unbalanced rigid object is determined as below after $F_{x}$ and $F_{y}$ are removed from Eq. (4) using Eq. (3):

$$
m \ddot{x}+c \dot{x}=R+F_{G}+F_{U} ;
$$

where

$$
\begin{gathered}
m=\left[\begin{array}{cccc}
m & 0 & m a & 0 \\
0 & m & 0 & m a \\
m a & 0 & I+m a^{2} & 0 \\
0 & m a & 0 & I+m a^{2}
\end{array}\right] \\
c=\left[\begin{array}{cccc}
0 & 0 & 0 & 0 \\
0 & 0 & 0 & 0 \\
0 & 0 & 0 & I_{z} \Omega \\
0 & 0 & -I_{z} \Omega & 0
\end{array}\right] \\
X=\left[\begin{array}{c}
X \\
Y \\
f_{X} \\
f_{Y}
\end{array}\right] F_{G}=\left[\begin{array}{c}
0 \\
m g \\
m g a
\end{array}\right] ; \\
F_{U}=\left[\begin{array}{c}
U F_{x} \\
U F_{y} \\
U M_{x} \\
U M_{y}
\end{array}\right]=\left[\begin{array}{c}
S \Omega^{2} \cos \left(\Omega t+f_{S}\right) \\
S \Omega^{2} \sin \left(\Omega t+f_{S}\right) \\
D \Omega^{2} \cos \left(\Omega t+f_{D}\right) \\
D \Omega^{2} \sin \left(\Omega t+f_{D}\right)
\end{array}\right] .
\end{gathered}
$$

Because of this mathematical model of the system considered can be rewriten as

$$
m \ddot{X}+c \dot{X}+k X=F_{G}+F_{U} .
$$

Partial solution of the equation below is

$$
m \ddot{X}+c \dot{X}+k X=F_{G} .
$$

Coordinates of balance position of the system is

$$
X_{S}=\left[\begin{array}{c}
X_{S} \\
Y_{S} \\
f_{X_{s}} \\
f_{Y_{s}}
\end{array}\right]=k^{-1} F_{G}
$$

If few symbols (notations) are used considering Fig. 2

$$
X=X_{S}+x
$$

equations of motion can be rewriten as

$$
m \ddot{x}+c \dot{x}+k x=F_{U}
$$

where,

$$
x=\left[\begin{array}{c}
x \\
y \\
f_{x} \\
y_{y}
\end{array}\right] .
$$

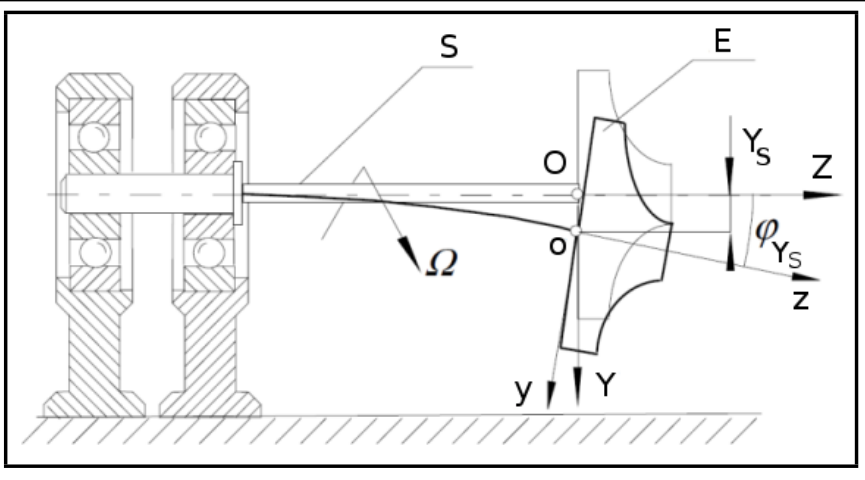

Figure 2. Sudden Position of the Disc As Fixed System Coordinates. ${ }^{14}$

Vector $x$ determines the sudden position of the disc as $x y z$ fixed system coordinates seen at Fig. 2. If Eq. (13) is written at Eq. (12);

$$
\begin{gathered}
m \ddot{x}+m a \ddot{f}_{x}+k_{11} x+k f_{x}=S \Omega^{2} \cos \left(\Omega t+f_{S}\right) \\
m \ddot{y}+m a \ddot{f}_{y}+k_{11} y+k f_{y}=S \Omega^{2} \sin \left(\Omega t+f_{S}\right) \\
\begin{array}{r}
m a \ddot{x}+\left(I+m a^{2}\right) \ddot{f}_{x}+I_{z} \Omega \dot{f}_{y}+k x+k_{22} f_{x} \\
=D \Omega^{2} \cos \left(\Omega t+f_{D}\right) \\
m a \ddot{y}+\left(I+m a^{2}\right) \ddot{f}_{y}-I_{z} \Omega \dot{f}_{y}+k_{y}+k_{22} f_{y} \\
=D \Omega^{2} \sin \left(\Omega t+f_{D}\right) .
\end{array}
\end{gathered}
$$

Complex forms of the equations of motion can be determined as below if right sides of Eqs. (14) or (15) are multiplied with unit vector $(i)$ and added to Eq. (15).

$$
\begin{array}{r}
m \ddot{z}+m a \ddot{f}_{z}+k_{11} z+k f_{z}=S \Omega^{2} e^{\left(\Omega t+f_{s}\right)} \\
m a \ddot{z}+\left(I+m a^{2}\right) \ddot{f}_{z}-i I \Omega \dot{f}_{z}+k z+k_{22} f_{z} \\
=D \Omega^{2} e^{i\left(\Omega t+f_{D}\right)}
\end{array}
$$

where,

$$
\begin{array}{r}
z=x+i y \\
f_{z}=f_{x}+i f_{y} .
\end{array}
$$

\section{EXPERIMENTAL STUDY}

\subsection{Exhaust Fan System}

In industry, cost and quality are gaining importance day, by day and efficiency is becoming a ciritical factor for success in rivalry environment. It is necessary to keep working performance of manufacturing systems at the highest level possible and making maintenance continuously with up-to-date maintenance techniques for corporations to work more efficiently. Predictive maintenance methods, which are being used widespreadly, vibration analysis, failure determinations, and removal activities from this methods are raising its importance in most of the corporations of today's rivalry environment. Important stipulations of industrial corporations include using predictive maintenance application methods effectively, correctly gathering data, interpreting in a timely manner, giving net decisions for results, and applying these decisions suitably to the techniques. 


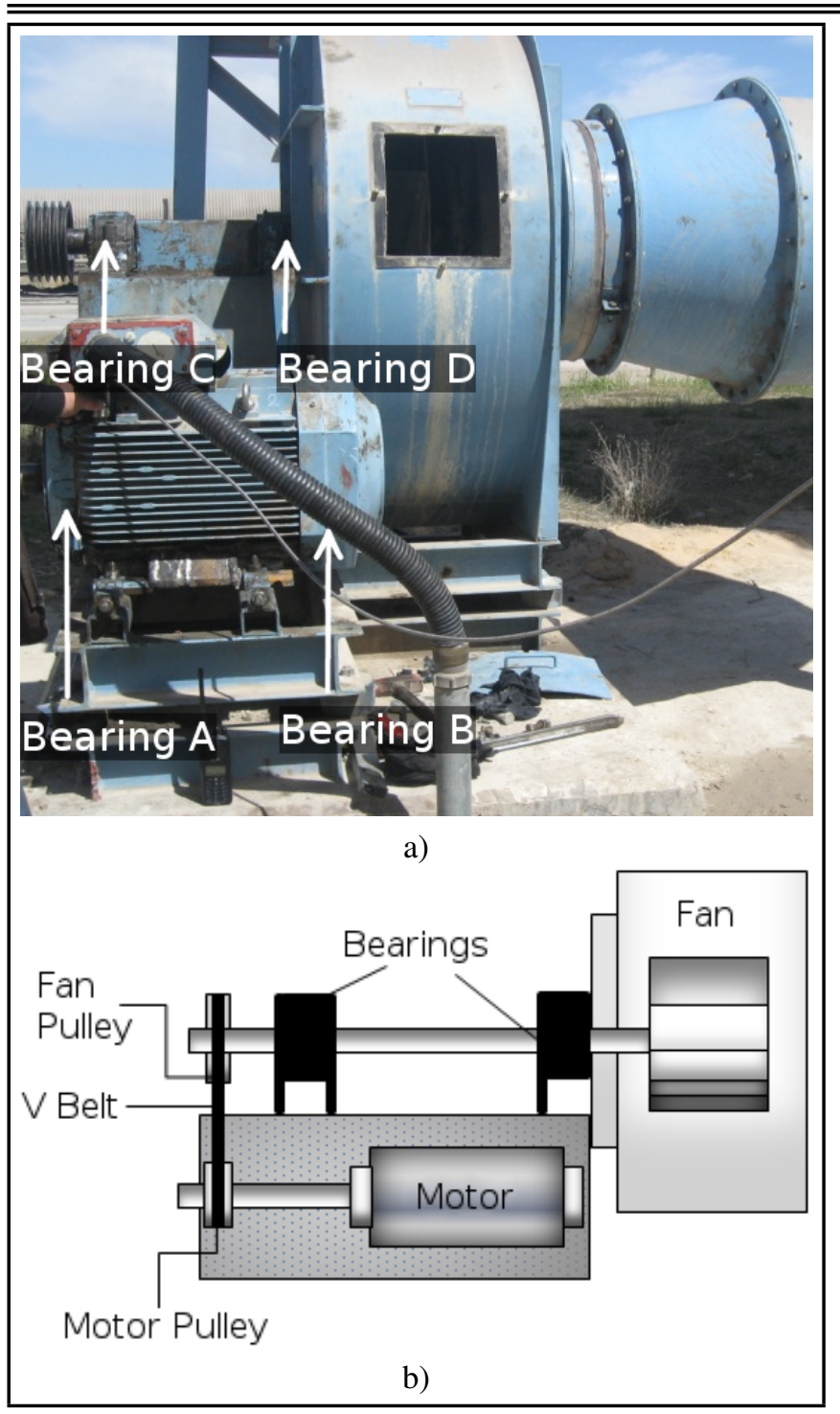

Figure 3. a) View of the exhaust fan system used on experimental study. b) Schematic representation of exhaust fan.

In this work, studies made to determine and to remove probable failures of the system with vibration analysis and determined results are summarized to the extent of predictive maintenance applications on exhaust fan systems.

\subsubsection{The information about fans used on experiment}

As shown in Fig. 3a, the exhaust fan system, situated on a flue gas purification system in Afsin Elbistan B Thermal Power Plant, has been used in experimental work. Repairing motor supports, changing the rubber damper, changing bearings, adjusting the pulley, and cleaning the dust on the fan of this system have been completed; additionally, an attempt has been made to minimize vibration on the fan by analyzing spectrum analysis graph.

\subsubsection{Technical features of the fan}

In this study, the vibration has been measured with DCXRT/ExpertAlert vibration analyzer. First, the information of exhaust fan has to be identified on the analyzer to measure vibration of the system.
Table 1. Technical features of fan.

\begin{tabular}{|c|c|}
\hline Trademark & Alfer Engineering ltd corp. \\
\hline Type/Size & AL-B3-630 \\
\hline Flow & $26000 \mathrm{~m}^{3} / \mathrm{h}$ \\
\hline Temperature & $20^{\circ} \mathrm{C}$ \\
\hline Total Pressure & $350 \mathrm{mmss}$ \\
\hline Year of manufacture & 2002 \\
\hline Fan Speed & $1723 \mathrm{rpm}$ \\
\hline Motor Speed & $1475 \mathrm{rpm}$ \\
\hline Motor & ABB Motors \\
\hline Diameter of motor pulley & $94 \mathrm{~mm}$ \\
\hline Diameter of fan pulley & $81 \mathrm{~mm}$ \\
\hline Length of belt & $2700 \mathrm{~mm}$ \\
\hline
\end{tabular}

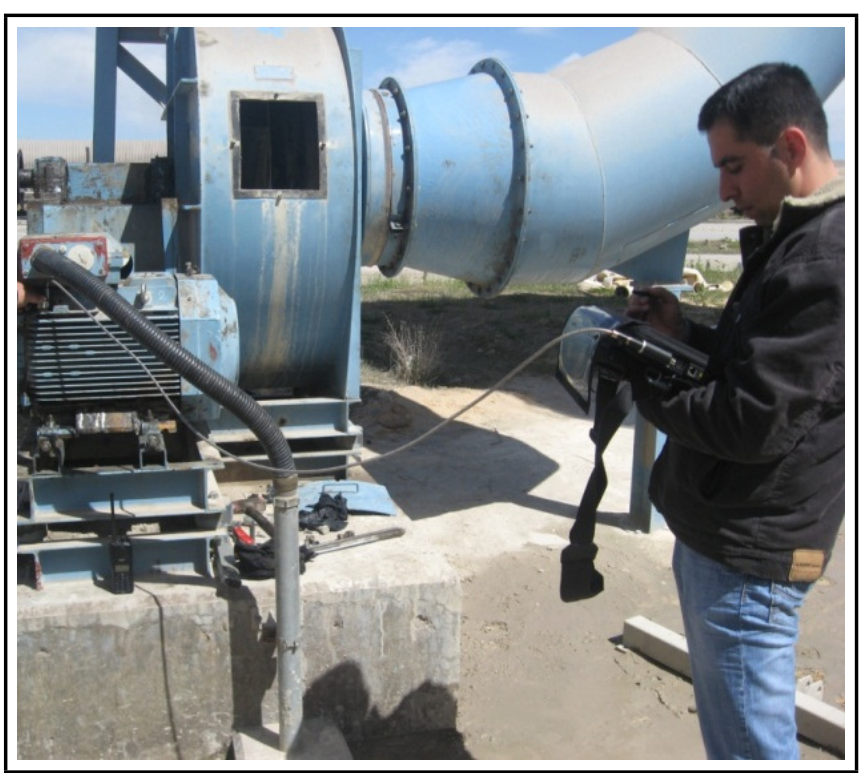

Figure 5. Measurement of vibrations of Bearing A.

\subsection{Measurements and Analysis on the Fan}

\subsubsection{The first measurement}

In the experimental analysis, vibration has been measured from four points on the fan bearings and motor bearings with analyzer before cracked motor supports havent been welded with arc welding and damaged fan bearings havent been replaced with new ones. After repair operations, ie., welding cracked motor supports (Fig. 4b), and replacing damaged fan bearings with new ones (Fig. 4c), vibration has been measured from four points again (Fig. 5). Second measurements showed the amplitude at the peak of $1 x$ increased. The belts have been demounted to identify whether the vibration was caused by fan or motor, and vibration of motor bearings have only been measured. As a result, analysis of the vibration showed that there was no problem on the motor. Third, demounted belts have been mounted again and performed necessary adjustments. When the vibration of bearings were measured again, it showed that the amplitude at the peak of $1 \mathrm{x}$ comparatively decreased. In addition, measurements showed that amplitude of vibration on Bearing A and Bearing B was high at the peak of $1 \mathrm{x}$ and amplitude of vibration on Bearing $\mathrm{C}$ and Bearing $\mathrm{D}$ was high at the peak of $1 \mathrm{x}, 2 \mathrm{x}, 3 \mathrm{x}$, and $4 \mathrm{x}$. It was found that worn or loose belt problems occurred at the third and fourth multiples of belt frequency. Misalignment of belt-pulley is seen at the peak of 2x, and mechnaical looseness 


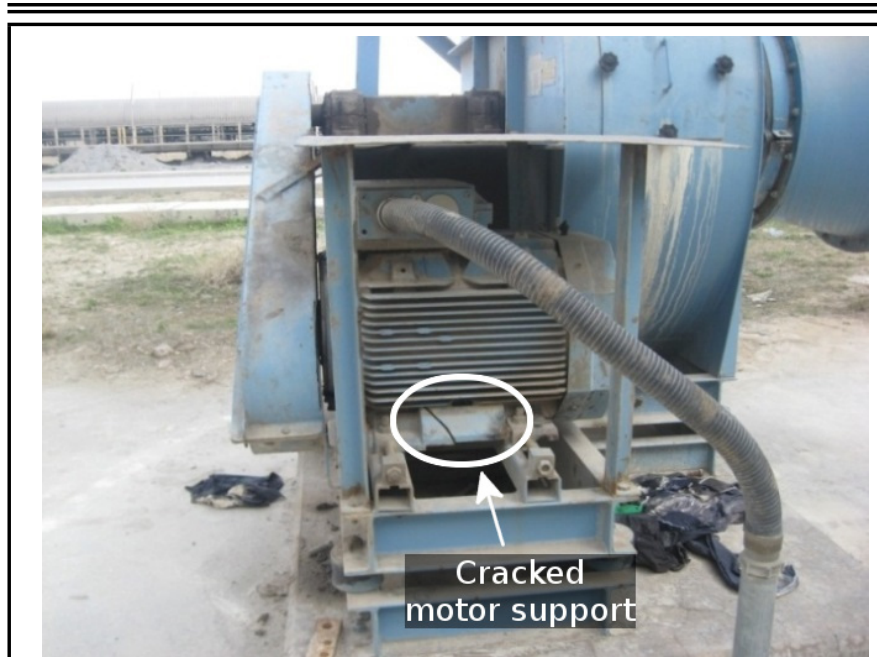

a)

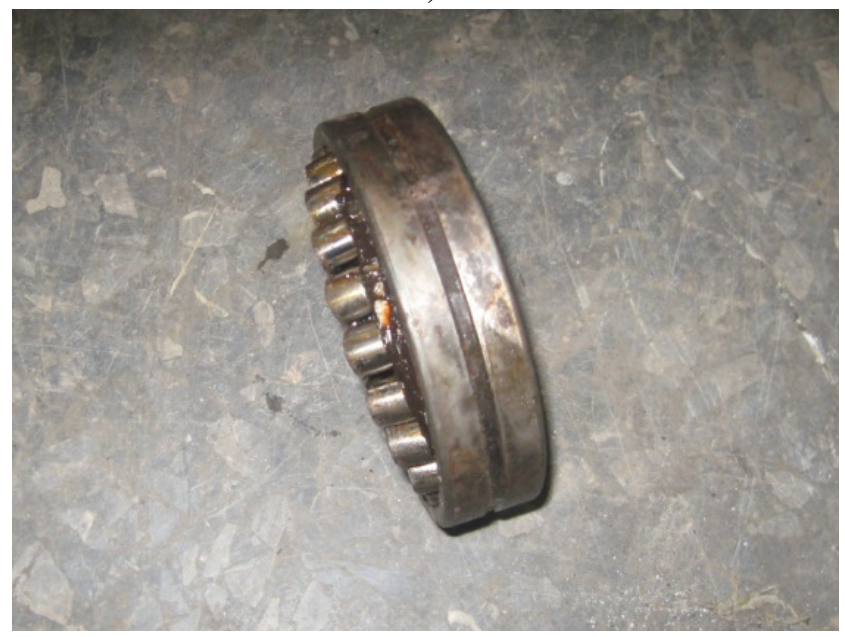

c)

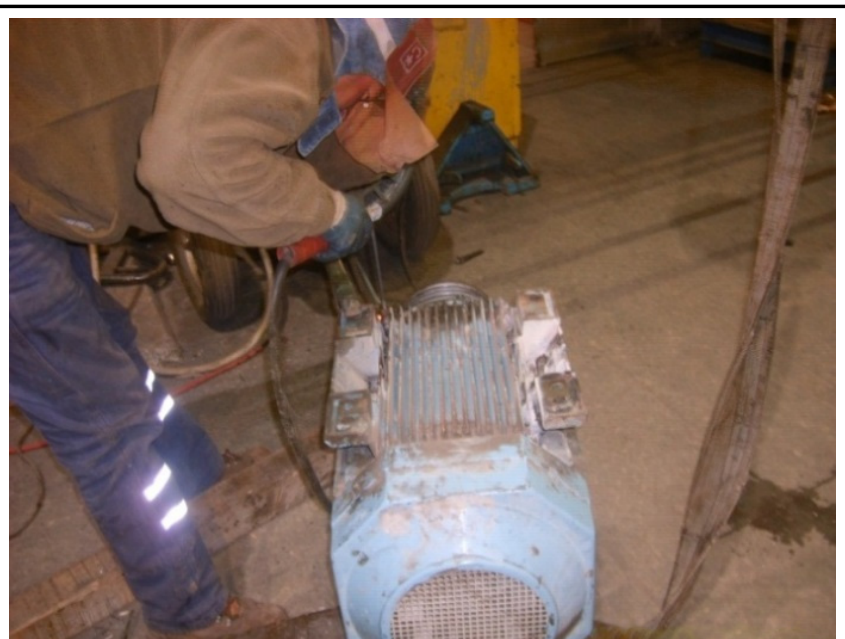

b)

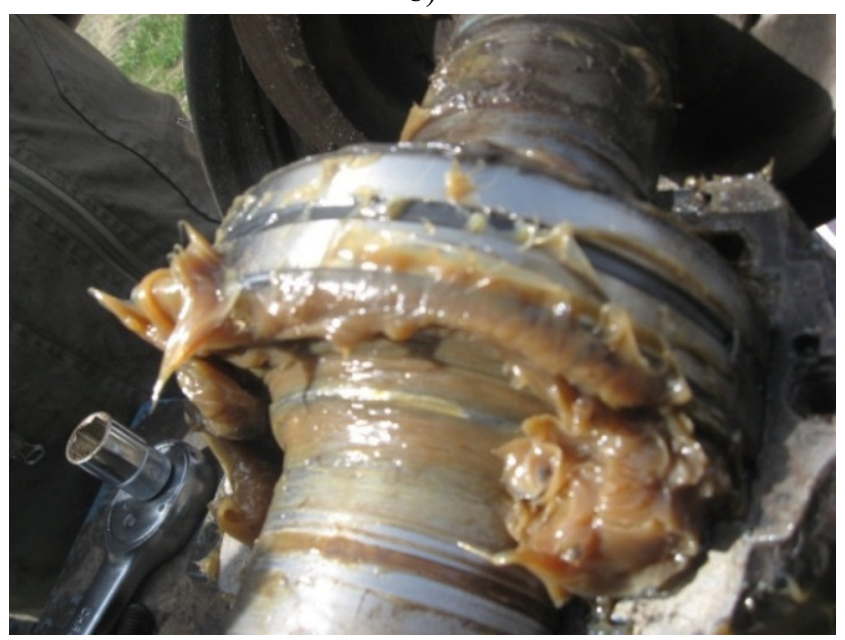

d)

Figure 4. a) Cracked motor support. b) Welding of cracked motor support. c) Damaged bearing. d) Mounting of new bearing.

is seen at the peak of $3 x$.

Belt Frequency $=(3,142 * 1723 \mathrm{rpm} * 81 \mathrm{~mm}) / 2700 \mathrm{~mm}=162$ $\mathrm{rd} / \mathrm{s}$

Fourth, bolts that fix the fan and motor to ground have been fastened. While the bolts were being fastened, it was discovered that the rubber dampers were sclerous, so that all nine rubber dampers have been changed. Finally, adustment of belt-pulley has been done and the vibrations have been measured again.

\section{RESULTS AND DISCUSSION}

\subsection{Results}

In the experimental study, vibration measurements have been done from four points on fan bearings and motor bearings, and results have been analyzed. By evaluation of the results, vibration values on four bearings have been minimized. Vibration values and graphs of the labeled four bearings have been respectively given for before maintenance and after maintenance.

As shown in Fig. 6, while the vibration value on the Bearing A was $20 \mathrm{~mm} / \mathrm{s}$ on one orders radial direction before maintenance, after maintenance the value decreased to $4 \mathrm{~mm} / \mathrm{s}$ (Fig. 7). In addition, it is clearly seen that while the vibration

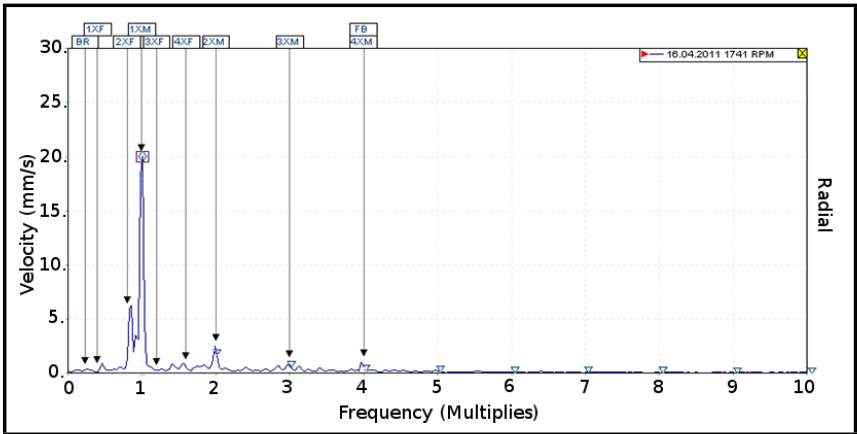

Figure 6. Spectrum analysis graph for Bearing A before maintenance.

value on Bearing B was $11 \mathrm{~mm} / \mathrm{s}$ on one order's axial direction before maintenance (Fig. 8), after maintenance the value decreased to $2 \mathrm{~mm} / \mathrm{s}$ (Fig. 9).

As shown in Fig. 10, the vibration value on the Bearing $\mathrm{C}$ was $15 \mathrm{~mm} / \mathrm{s}$ on one orders radial direction before maintenance, and after maintenance the value have been decreased to $3 \mathrm{~mm} / \mathrm{s}$ (Fig. 11). In addition, it is clearly seen that while the vibration values on the Bearing D were 11.5 and $12 \mathrm{~mm} / \mathrm{s}$ on one orders radial and axial direction before maintenance, respectively (Fig. 12 and Fig. 14); after maintenance, the values have been decreased to $8 \mathrm{~mm} / \mathrm{s}$ and $1 \mathrm{~mm} / \mathrm{s}$, respectively 


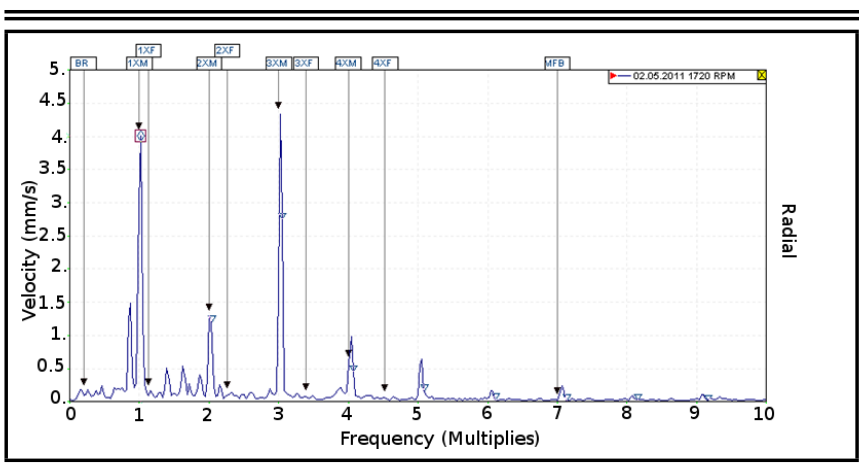

Figure 7. Spectrum analysis graph for Bearing A after maintenance.

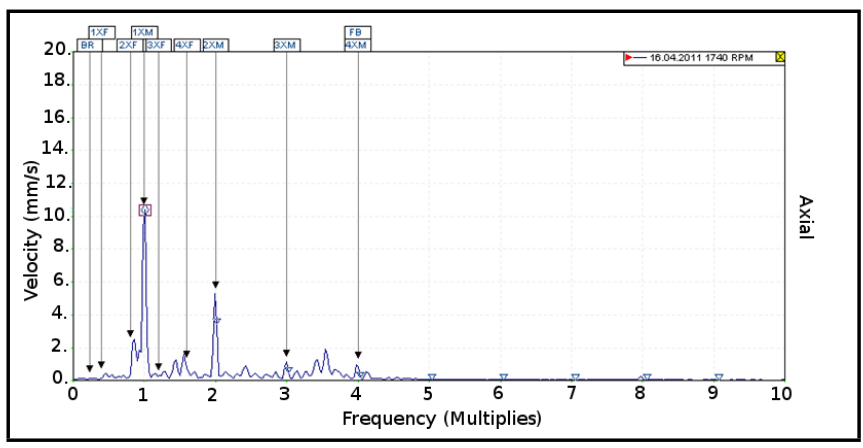

Figure 8. Spectrum analysis graph for Bearing B before maintenance.

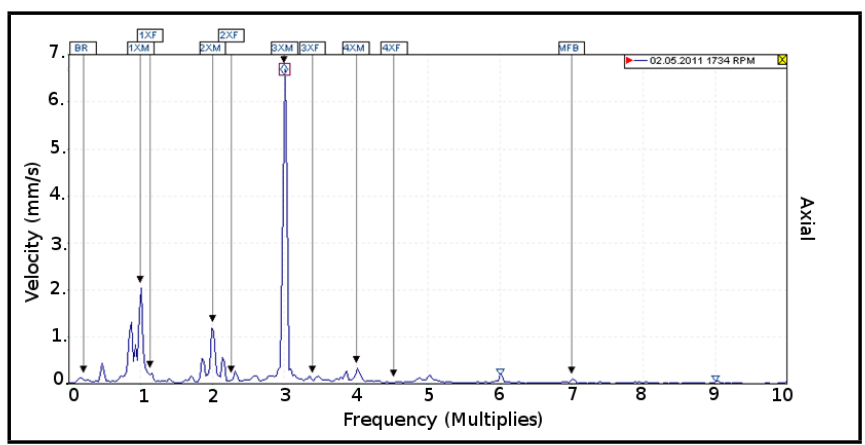

Figure 9. Spectrum analysis graph for Bearing B after maintenance.

Table 2. Vibration values before and after maintenance.

\begin{tabular}{||c|c|c|c||}
\hline $\begin{array}{c}\text { Measurement } \\
\text { point }\end{array}$ & $\begin{array}{c}\text { Vibration } \\
\text { values } \\
\text { before } \\
\text { maintenance }\end{array}$ & $\begin{array}{c}\text { Vibration } \\
\text { values } \\
\text { after } \\
\text { maintenance }\end{array}$ & $\begin{array}{c}\text { Percentage } \\
\text { of } \\
\text { change }\end{array}$ \\
\hline Bearing A (radial) & $20 \mathrm{~mm} / \mathrm{s}$ & $4 \mathrm{~mm} / \mathrm{s}$ & $80,00 \%$ \\
\hline Bearing B (axial) & $11 \mathrm{~mm} / \mathrm{s}$ & $2 \mathrm{~mm} / \mathrm{s}$ & $81,80 \%$ \\
\hline Bearing C (radial) & $15 \mathrm{~mm} / \mathrm{s}$ & $3 \mathrm{~mm} / \mathrm{s}$ & $80,00 \%$ \\
\hline Bearing D (radial) & $11,5 \mathrm{~mm} / \mathrm{s}$ & $8 \mathrm{~mm} / \mathrm{s}$ & $30,43 \%$ \\
\hline Bearing D (axial) & $12 \mathrm{~mm} / \mathrm{s}$ & $1 \mathrm{~mm} / \mathrm{s}$ & $91,67 \%$ \\
\hline
\end{tabular}

(Fig. 13 and Fig. 15). Consequently, vibration values have been markedly reduced after analysis and maintenance procedures had been done (Table 2).

\subsection{Discussion}

When unexpected failures occur on machines, maintenance takes longer because of the level of difficulty and time consuming of assurance of relay. This leads to storing extra relay for factories that do not perform planned and programmed maintenance. Storing extra relay increases cost and creates additional cost for finished shelf life of relays. Relay can be provided on

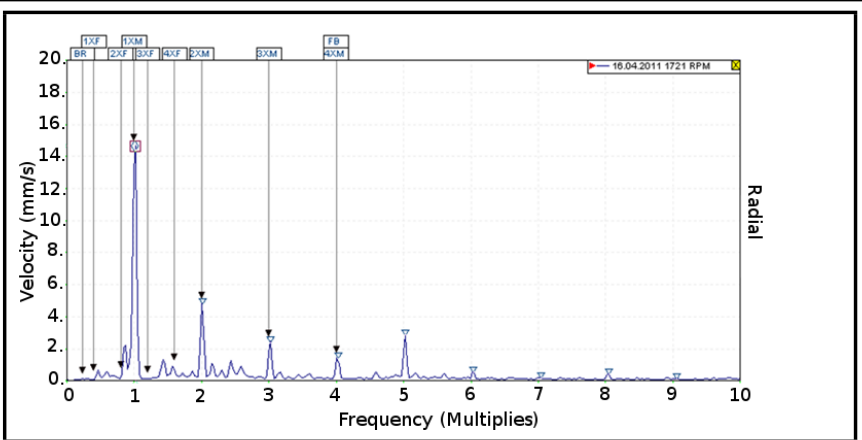

Figure 10. Spectrum analysis graph for Bearing $\mathrm{C}$ before maintenance.

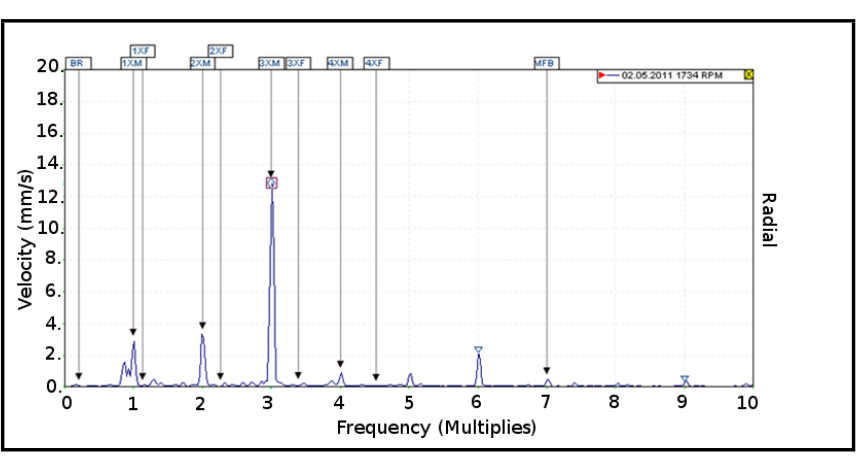

Figure 11. Spectrum analysis graph for Bearing $\mathrm{C}$ after maintenance.

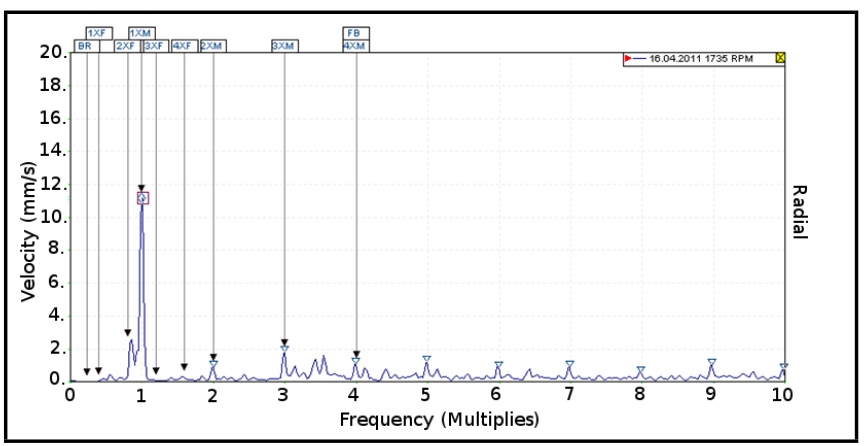

Figure 12. Spectrum analysis graph for Bearing D before maintenance (radial).

time by using predictive maintenance method; the machine is monitored constantly, and time of faults can be predicted so that it doesn't need to store extra relay.

As seen in Table 2, while vibration value before maintenance on Bearing A was $20 \mathrm{~mm} / \mathrm{s}$, this value decreased to $4 \mathrm{~mm} / \mathrm{s}$ after maintenance. The same situation can be also seen for other bearings. The largest decline on Bearing D was $91.67 \%$. It can be said that Bearing D damaged largely before maintenance. This situation shows that predictive maintenance has high importance.

The cost of labor can be reduced by using predictive maintenance method rather than industries employing extra workers to run after failures because of sudden machine failures.

Although the equipment and specialists required for predictive maintenance method may seem to be an increase in cost, the difference will payoff in a short time. Overall, predictive maintenence method decreases cost and production loss. 


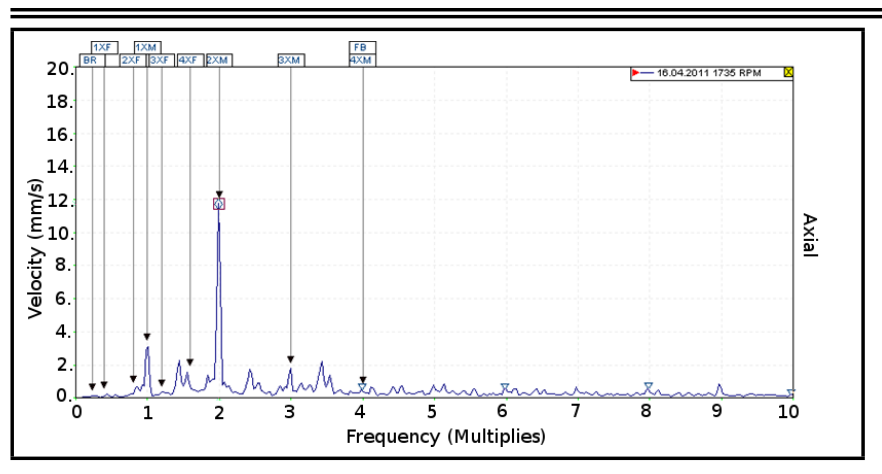

Figure 13. Spectrum analysis graph for Bearing D after maintenance (radial).

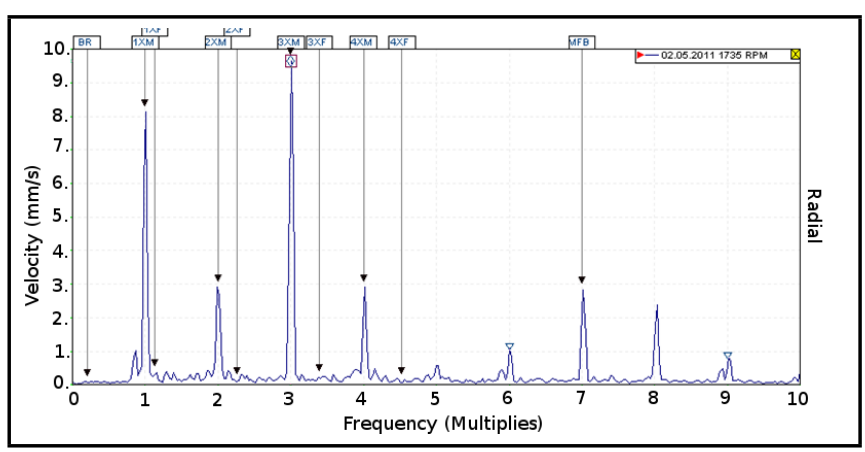

Figure 14. Spectrum analysis graph for Bearing D before maintenance (axial).

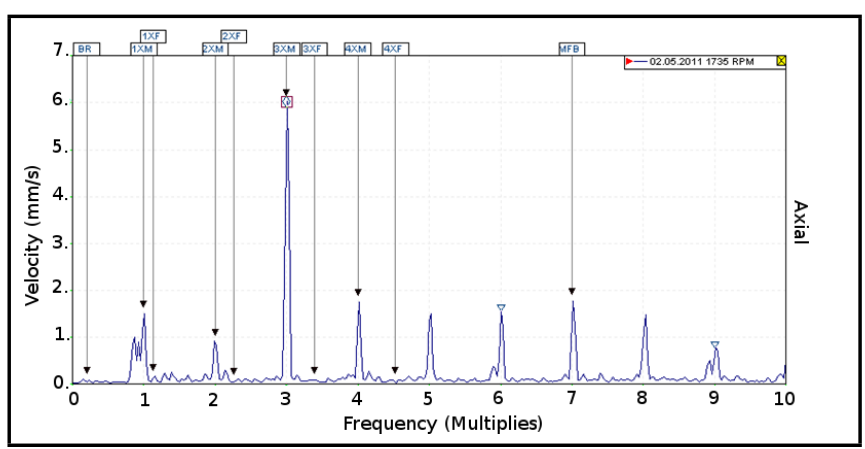

Figure 15. Spectrum analysis graph for Bearing D after maintenance (axial).

\section{REFERENCES}

1 Tsang AHC. Condition-based maintenance: tools and decision making. J. Quality Maintenance Eng, 3-17, (1995). http://dx.doi.org/10.1108/13552519510096350

2 Girdhar, P., Scheffer, C., In practical machinery vibration analysis and predictive maintenance, Oxford, (2004). http://dx.doi.org/10.1016/b978-075066275-8/50001-1

3 I. E. Alguindigue, L. A. Buczak, R. E. Uhrig, Monitoring and diagnosis of rolling element bearings using artificial neural networks, IEEE Trans Ind Electron, 40 (2), 209-217, (1993). http://dx.doi.org/10.1109/41.222642
${ }^{4}$ Orhan, S., Aktürk, N., Çelik, A., Vibration monitoring for defect diagnosis of Rolling element bearings as a predictive maintenance tool: Comprehensive case studies, NDT\&E International, 39, 293-298, (2006). http://dx.doi.org/10.1016/j.ndteint.2005.08.008

5 Trebuna, F., Simcak, F., Bocko, J., Hunady, R., Pastor, M., Complex approach to the vibrodiagnostic analysis of excessive vibration of the exhaust fan, Engineering Failure Analysis, 37, 86-95, (2014). http://dx.doi.org/10.1016/j.engfailanal.2013.11.015

${ }^{6}$ McFadden, P. D., Smith, J. D., Model for the vibration produced by a single point defect in a Rolling element bearing, Journal of Sound and Vibration, 96(1a), 69-82, (1984). http://dx.doi.org/10.1016/0022-460x(84)90595-9

7 Aktürk, N., Gohar, R., The effect of Ball Size Variation on Vibrations Associated with Ball-Bearings, Proc. I. Mech. E., 212 Part j, 101-109, (1998). http://dx.doi.org/10.1243/1350650981541921

8 Ibrahim, I., Rani, A. M. A., Zainuddin, A., Anua, M. R. M., Centrifugal compressor cooler fan high vibration: a case study, Australian Journal of Mechanical Engineering, 9 (1), 1-9, (2012). http://dx.doi.org/10.1080/14484846.2012.11464613

9 Geramitchioski, T., Trajcevski, L., Prediction of rolling bearings defect in motor-fan using vibration signal analysis, Machine Design, 3 (3), 211-216, (2011).

10 Albraik, A., Althobiani, F. G., Ball, A., Diagnosis of centrifugal pump faults using vibration methods, Journal of Physics: Conference Series, 364, 2012. http://dx.doi.org/10.1088/1742-6596/364/1/012139

11 Spychala, J., Szczekala, M., Zokowski, M., Diagnosis of the jet-propelled engine by vibration analysis, Transport Problems, 4 (3), 75-81, (2009).

12 Choi, B., Kim, H., Gu, D., Kim, H., Jeong, H., Diagnosis of cryogenic pump-motor systems using vibration and current signature analysis, Journal of Mechanical Science and Technology, 20 (7), 972-980, (2006). http://dx.doi.org/10.1007/bf02915996

13 Ali, M. K., Youssef, M. F. H., Hamaad, M. A., El Butch, A. A., A study on fault diagnosis by vibration analysis at different loading and speed conditions, ASAT-13, 13, 1-11, (2009).

14 J. M. Krodkiewski, Dynamics of Rotors, The University of Melbourne, Department of Mechanical Engineering, (2000). 